\title{
The measurement of hair growth as an index of protein synthesis in malnutrition
}

\author{
By R. T. SIMS* \\ Department of Paediatrics and Child Health, University of Natal, Durban
}

(Received I 2 September 1967-Accepted 28 December I967)

\begin{abstract}
I. The purpose of this paper is to propose the measurement of scalp hair diameter as a useful index of protein synthesis in the management of cases of malnutrition.

2. Observations on scalp hair from ten control infants showed that each hair tapered very gradually towards its free end.

3. Observations on scalp hair from twenty-six infants with kwashiorkor showed that each hair narrowed towards the follicle; the effect was statistically significant.

4. After I month's treatment for kwashiorkor, scalp hair thickened towards the follicle and the effect was statistically significant.

5. Serial measurements of the greatest diameter at $0.5 \mathrm{~mm}$ intervals along the hair shaft had a main trend which was related to nutritional history.

6. The period of time over which narrowing of the hair shaft took place was calculated from the rate of hair growth and the serial diameter measurements: this time was always longer than the history of kwashiorkor.
\end{abstract}

Kwashiorkor is a disease of infancy associated with diets deficient in proteins (Williams, 1933). Histological and biochemical observations on patients with kwashiorkor are consistent with a reduction of protein synthesis by all the tissues of the body. The general pathological evidence has been reviewed by Gillman \& Gillman (I95 I) and Trowell, Davies \& Dean (1954). The biochemical changes in kwashiorkor have been reviewed by Waterlow, Cravioto \& Stephen (1960).

One of the problems in designing clinical trials for research on malnutrition is the choice of objective tests of the condition of patients when they first present and of their response to treatment. Garrow \& Pike (1967) have found that in severe malnutrition of infants weight, oedema and haemoglobin concentration are not related to mortality or to rate of recovery. Gillman \& Gillman (I95I) performed serial biopsies on the livers of patients with kwashiorkor receiving different diets. They found that the fat content of liver cells gave a more reliable indication of a patient's condition than the clinical picture. Other workers, such as Thompson (1955), have used the plasma protein concentration as a measure of their patients' response to different treatments. The purpose of this paper is to propose the measurement of hair diameters as a useful index of protein synthesis in the management of cases of malnutrition. It is the second of a series of investigations on hair changes in kwashiorkor. The first investigation showed that there were reductions of hair-shaft diameters and growth rates in twelve established cases of kwashiorkor compared with twelve matched controls (Sims, I967 b). The $95 \%$ confidence intervals for the means of the largest and smallest diameters of the kwashiorkor hair shafts just above the levels of the follicles were $50 \pm 6$ $\mu \mathrm{m}$ and $29 \pm 3 \mu \mathrm{m}$. No detectable hair growth occurred for 2 days or more in eight of

* Present address : Anatomy School, Downing Street, Cambridge. 
the twelve patients. The $95 \%$ confidence interval for the mean length of hair grown in the first Io days growth was $\mathrm{I} \cdot 3 \pm 0.3 \mathrm{~mm}$. For the controls the $95 \%$ confidence intervals of the means of the largest and smallest diameters were $77 \pm 6 \mu \mathrm{m}$ and $39 \pm 1$ $\mu \mathrm{m}$, and that for the length of hair grown in ro days $2 \cdot 3 \pm 0.125 \mathrm{~mm}$.

\section{MATERIALS AND METHODS}

Specimens of hair were taken from thirty-six Zulu children between $\mathrm{I}$ and 5 years of age admitted to the King Edward VIII Hospital, Durban. Twenty-six of these were in the Paediatric Unit suffering from kwashiorkor and ten were boarders at the hospital receiving physiotherapy for post-poliomyelitic paralysis.

The criteria used for the diagnosis of kwashiorkor were (I) evidence that the previous diet had been deficient in protein, (2) oedema associated with hypoalbuminaemia, (3) mental changes towards apathy and irritability, (4) the dermatosis of kwashiorkor, and (5) retarded growth. The patients were under the care of Dr Joan Scragg, who has published a detailed survey of the clinical picture of kwashiorkor seen at the King Edward VIII Hospital (Scragg \& Rubidge, I960).

The only convenient group of children known to be free of active disease and on an adequate balanced diet were the boarders who resided at the hospital because their homes were too far away for them to make daily visits for physiotherapy. They were used as controls and were selected to match the kwashiorkor patients as closely as possible in respect of sex and age.

A sample of hair was plucked from each patient's scalp in the region of the vertex. It was possible to pluck hair from the kwashiorkor patients with minimal force but the control specimens were obtained with a short pull of considerable force. Care was taken not to deform the shafts during handling. The hair was dehydrated in absolute ethanol, washed in xylol to remove fat, then rinsed in absolute ethanol and allowed to dry. Each hair was laid straight on a microscope slide and held in position by another slide resting on top of it. Under these conditions the hair has its greatest diameter parallel to the surface of the slide.

Observations on the hairs were all made on the greatest diameter at any point along the shaft. A Watson Bactil microscope was used (W. Watson and Sons Ltd, Barnet, Herts) with a Watson Image Shearing Eyepiece (WISE). The WISE gives two parallel images of the hair, one of which is orange and the other blue. The images can be moved by a calibrated dial and, when they touch, the diameter of the hair is given on the calibrated dial. It is possible to ensure that the greatest diameter of the hair is being measured by looking at the apposing edges of the orange and blue images. Both edges are sharply in focus together only when the greatest diameter of the hair is at right angles to the path of light in the microscope. Measurements were made to the nearest $\mu \mathrm{m}$ at a magnification of 200 times. The distances of measurements from the hair bulb were taken from a Vernier scale on the moving stage of the microscope.

The growth rate of hair was measured on a circular area of the scalp about $3 \mathrm{~cm}$ in diameter situated over the bregma. The area was shaved carefully so that no hair was visible above the skin surface. Ten days later the length of hair projecting above the 
skin surface was measured with a hand-lens with a focal length of $5 \mathrm{~cm}$ and an ocular micrometer. A square with sides $\mathrm{I} \mathrm{cm}$ long and subdivided into $\mathrm{mm}$ was engraved on the micrometer. It was held firmly against the scalp and the length of the projecting hair was measured to the nearest $0.25 \mathrm{~mm}$. The treatment of the patients was started immediately they were admitted to the hospital so the growth rate measured was for the first ro days of treatment. This would not be less than the growth rate before treatment.

\section{RESULTS}

\section{Controls}

Hairs plucked from the scalps of the ten control infants were surveyed with the WISE from the hair bulb to their free end. The surveys showed that each hair gradually diminished in diameter from the bulb to the free end. The rate of change in diameter was so slight that for distances less than about Io $\mathrm{mm}$ near the bulb the diameter seemed to be constant. At the free end the changes of diameter were more marked.

Table I. Mean ( $(\overline{\mathrm{d}})$ and standard error $(S E)$ of the differences in $\mu m$ between the diameter in the follicle and that $10 \mathrm{~mm}$ away for ten hairs: $\mathrm{P} \%$ is the probability that the mean of the differences is zero by Student's t test

Kwashiorkor patients

$\begin{array}{lll}\overbrace{\bar{d}} & \text { SE } & P \% \\ 2 \cdot 2 & \mathrm{I} \cdot 2 & >10 \\ 0.2 & 0.15 & >10 \\ 2 \cdot 1 & \mathrm{I} \cdot 3 & >10 \\ \mathrm{I} \cdot 8 & \mathrm{I} \cdot 3 & >10 \\ 0.1 & 0.3 & >25 \\ 0.7 & \mathrm{I} \cdot 0 & >25\end{array}$

\begin{tabular}{|c|c|c|c|c|c|}
\hline \multicolumn{3}{|c|}{ On admission } & \multicolumn{3}{|c|}{ I month later } \\
\hline $\bar{d}$ & $\mathrm{SE}$ & $P \%$ & $\bar{d}$ & $\mathbf{S E}$ & $P \%$ \\
\hline$-6 \cdot I$ & $1 \cdot 0$ & $<0.2$ & $7 \cdot 0$ & $1 \cdot 2$ & $<\mathrm{I} \cdot \mathrm{O}$ \\
\hline$-5 \cdot 4$ & $1 \cdot 0$ & $<\mathrm{I} \cdot \mathrm{O}$ & $8 \cdot 3$ & $1 \cdot 7$ & $<\mathbf{I} \cdot \mathbf{O}$ \\
\hline$-\mathrm{I} 2 \cdot 3$ & $4 \cdot 7$ & $<5.0$ & 13.7 & $I \cdot 8$ & $<0.1$ \\
\hline-9.4 & $2 \cdot 3$ & $<\boldsymbol{1} \cdot 0$ & 10.3 & $2 \cdot 0$ & $<\mathrm{I} \cdot \mathrm{O}$ \\
\hline$-12 \cdot 7$ & $3 \cdot 3$ & $<2.0$ & II $\cdot 6$ & $\mathbf{I} \cdot 9$ & $<0.2$ \\
\hline$-1 x \cdot 6$ & $2 \cdot 9$ & $<I_{1} \cdot 0$ & $9 \cdot 7$ & $\mathbf{I} \cdot 8$ & $<I \cdot O$ \\
\hline
\end{tabular}

Ten hairs were plucked from the vertex of the scalp in each of six control infants. The diameters of the hairs were measured just above the hair bulb and ro $\mathrm{mm}$ away from it. 'Then the Student's $t$ test was used to test the hypothesis that the differences between the two measurements on each hair were random with a mean value of zero. The results of these measurements are summarized in Table I. All the mean differences were positive but not significantly different from zero.

Serial measurements of the greatest diameter were made at $0.5 \mathrm{~mm}$ intervals from the bulb of one hair from each control infant. The results for all the hairs were similar and are shown graphically in Fig. I. Obviously the hair-shaft diameter was almost constant with small deviations.

\section{Patients on admission to hospital}

Hairs plucked from the scalp of the twenty-six patients on admission to hospital were surveyed with the WISE. The surveys showed a definite increase in diameter for 
up to $40 \mathrm{~mm}$ from the bulb towards the free end of the hair. The diameter reached a maximum and then gradually decreased at a distance from the bulb which varied from patient to patient.

Ten hairs were plucked from the vertex of the scalp in each of the first six of these patients admitted to the hospital. The greatest diameters of the hairs were measured just above the hair bulb and ro mm away from it. The results of these measurements are summarized in Table $\mathbf{I}$. All the mean differences were negative and significantly different from zero at the $5 \%$ level of probability.

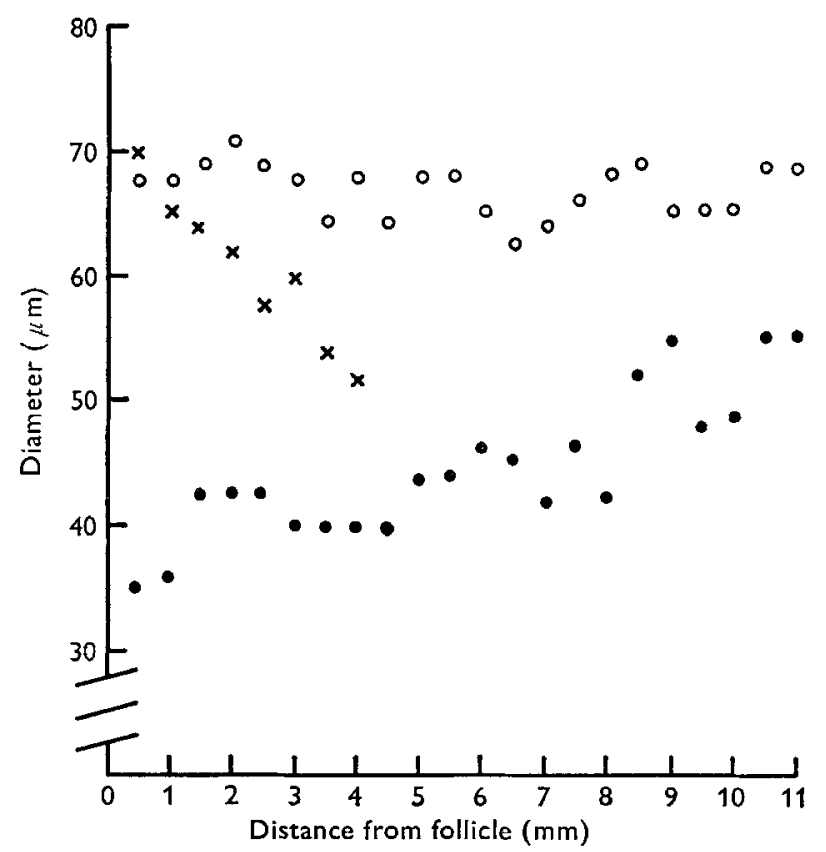

Fig. I. Graph of the greatest diameter of a hair from a control patient ( $O$ ), from a patient with kwashiorkor (O) and from a patient after $\mathrm{r}$ month's treatment for kwashiorkor $(x)$ plotted against the distances from the bulb of the follicle.

Three hairs were plucked from the scalp of the next six patients admitted and an area of scalp was shaved for measurements of growth rate. Serial measurements of the greatest diameter of the hairs were made at intervals of $0.5 \mathrm{~mm}$ from the hair bulb. The results of these measurements are shown in Fig. I. It can be seen that the hair shaft narrowed as the bulb was approached.

Observations were made on the shaved areas of scalp ro days after it was shaved. The length of hair protruding above the skin surface was measured to the nearest $0.25 \mathrm{~mm}$. From the growth rate of the hair and the distance along the hair shaft to the maximum diameter the date of the first change was estimated. Then the history of the patient was checked to see whether the onset of symptoms was before, after or coincident with the first hair change. The results are recorded in Table 2 and show that narrowing of hair preceded the onset of symptoms in each case examined. 


\section{Patients after I month's treatment}

Hairs plucked from six patients after I month's treatment were surveyed with the WISE from the hair bulb to the free end. All the hairs were taken from the shaved area of scalp. Attempts to pluck hair from the unshaved region were frustrated because the shafts invariably broke above the level of the hair bulb. The greatest diameters of the ten hairs from each patient were rneasured just above the bulb and at the shaved end. The results of the measurements are summarized in Table I. All the mean differences were positive and significantly different from zero at the $5 \%$ level of probability.

Serial measurements were made of the greatest diameter at $0.5 \mathrm{~mm}$ intervals from the bulb of one hair from each infant. The results from all the hairs were similar to that shown in Fig. I. The greatest diameter of the hair shaft increased rapidly as the bulb was approached.

\section{DISCUSSION}

The observations on the material from the ten control infants show that each hair tapered towards its free end. Near the follicle the degree of tapering was less than at the free end. There is no evidence in the present work that indicates whether this gradual change in diameter is a result of an increase in shaft diameter with length of hair grown or a result of age and wear on the exposed fibre. The application of Student's $t$ test to the diameter change near the follicle gave some interesting results. The null hypothesis tested was that the mean diameter of the hair was constant and that small deviations from the mean occur by chance. If the assumption is true and measurements are made in pairs then the sum of the differences between the two members of the pairs would equal zero. If the sum of the differences does not equal zero, then the original assumption of a constant mean is discredited. The results of the tests on hair from each control infant in Table I did not discredit the assumption since the probabilities were all greater than $10 \%$. But we know from the surveys of the hairs that in fact they gradually tapered. The paradox arises because the change in diameter is so gradual in relation to the difference between hairs that the test is not sufficiently sensitive to detect it on a small sample of ten. When the results for the six control infants are considered together as six samples of ten, the expected result is obtained. If the mean diameter of the hair is constant the chance of obtaining a mean difference between the two measurements that is greater than zero is half. The chance of obtaining six samples that all have a mean difference greater than zero is $100\left(\frac{1}{2}\right)^{6}$ which is $\mathrm{I} \cdot 6 \%$. Thus the assumption is discredited at the $5 \%$ level of significance when a larger amount of evidence is considered.

The specimens taken from the twenty-six patients with kwashiorkor when they were admitted to hospital showed that their hair narrowed towards the follicle. The statistical tests of the null hypothesis that the mean diameter of the hair was constant gave probabilities of less than $5 \%$ for all six patients and indicated that the mean diameter of the hair changed. The means of the differences between the two measurements on each hair were all negative and emphasized that the hair tapered in the opposite 
direction to that of the hair of the control infants. The proposal that measurement of hair could be used for diagnostic purposes is made with confidence because hair specimens taken from all twenty-six patients with kwashiorkor narrowed towards the follicle.

The hairs taken from the six patients after I month's treatment thickened towards the follicle. The hypothesis that their mean diameter was constant was discredited by the $t$ test and the probabilities of it being true were all less than I \%. Unlike the results for the controls, the test was sufficiently sensitive to detect the change in diameter on a sample of ten hairs from these patients because the mean differences were greater.

Table 2. Observations on six patients with kwashiorkor on the rate of hair growth and the distance from the hair bulb along the hair to the maximum hair diameter

(The number of weeks to the first reduction of hair diameter has been calculated for comparison with the length of illness from the history given by each patient's mother)

$\begin{array}{cccc}\begin{array}{c}\text { Length } \\ \text { of hair } \\ \text { grown in } \\ \text { Io days } \\ \text { (mm) }\end{array} & \begin{array}{c}\text { Distance } \\ \text { from } \\ \text { bulb to } \\ \text { maximum } \\ \text { shaft } \\ \text { diameter } \\ \text { (mm) }\end{array} & \begin{array}{c}\text { No. of } \\ \text { weeks of } \\ \text { abnormal } \\ \text { hair } \\ \text { growth }\end{array} & \begin{array}{c}\text { Length of } \\ \text { illness } \\ \text { (weeks) }\end{array} \\ 0.0 & 35 & ? & 6 \\ 0.5 & 12 & 34 & 4 \\ 0.5 & 6 & 17 & 4 \\ 0.75 & 10 & 19 & 12 \\ 0.75 & 9 & 17 & 8 \\ 1.0 & 6 & 9 & 4\end{array}$

It has been established that hair has an almost constant diameter in control infants, narrows in patients with kwashiorkor, and thickens in patients after treatment for kwashiorkor. This indicated that serial measurements along the hair shaft would show progressive changes that could be related to time by the idea of the bulb date enunciated in previous work (Sims, $1967 a$ ). The hair shaft is formed from a column of cells which move in an orderly fashion out of the hair bulb. The distance of any cell from the bulb is determined by the date on which it began to move and the rate of hair growth. If the distance from the bulb to a point on the hair shaft is divided by the rate of hair growth then the date on which that point began to move out of the bulb is obtained.

The results of serial diameter measurements at $0.5 \mathrm{~mm}$ intervals along the hair from the bulb are shown in Fig. I. The main trend of the curve for the control infant was almost parallel to the $x$-axis. This is compatible with the idea of an almost constant mean diameter. The main trend of the curve for the patients after I month's treatment was a negative slope at a definite angle to the $x$-axis. The hair bulb is at the origin of the graph and the bulb date of the points to the right of the origin go progressively farther back in time, so the curve represents the increase in shaft diameter that occurred during treatment. None of the patients studied stayed in hospital longer than I month and none showed a return to an almost constant hair diameter. This is 
objective confirmation of the clinical impression that hair does not completely recover in this time. Gillman \& Gillman (I95I) found that fat was still present in cells of the liver when patients were discharged as cured on clinical evidence. Clinicians know that a prolonged period of convalescence is necessary for complete recovery from kwashiorkor, as these observations show.

The curves for the hair of the kwashiorkor patients on admission to hospital had a positive slope. The interpretation of these slopes in terms of bulb date is that as time progresses farther into the past the hair diameter becomes thicker. Because the growth rate of the hair was measured in these patients, it was possible to calculate the longest time over which narrowing of the hair could have occurred (Table 2). In every instance it was found that hair formed before the onset of symptoms showed a reduction in diameter. This indicates that a measurable reduction of hair diameter precedes other more obvious changes of kwashiorkor. A reservation must be applied to the validity of this conclusion because the date of onset of symptoms was obtained from the patients' mothers and time is not an important dimension for many Zulus. If the conclusion of this retrospective study is confirmed, hair growth rate will be a valuable measure of nutritional status in suspect populations.

There is no index of the condition of a patient with malnutrition that is completely satisfactory (Garrow \& Pike, 1967). Body height is unsatisfactory because it is only one of the three linear dimensions of the body. The three dimensions do not vary proportionately, and even if they did the height component of volume increase would be a root of a cubic equation and hence relatively small. Body-weight is misleading because the amount of water in the body is so variable. Smith (1960) has shown that body-weight can overestimate body solids by about $250 \%$. The concentration of plasma proteins overestimates protein synthesis in the body as a whole because of excessive re-utilization of amino acids and changes in the protein distribution between the vascular and extravascular fluids. Measurements of hair growth underestimate protein synthesis in the body as a whole. It was shown in the first investigation of this series that hair growth stops completely before the decline of a patient's condition is irreversible (Sims, $1967 b$ ). Waterlow (1959) has shown that the skin of malnourished rats contributes less to synthesis of total body protein than the skin of well-fed controls. There is a change in the distribution of protein synthesis in malnutrition which renders unlikely the possibility of discovering any one organ that will be representative of the body as a whole.

The commendable features of the measurement of hair diameters and hair growth as an index of protein synthesis are all concerned with the ease of its execution. It is easy to obtain specimens of hair and they require the minimum of preparation before measurements are made. The apparatus required is simple. Although a Watson Image Shearing Eyepiece was used in this investigation it is possible to use an ocular micrometer in any ordinary microscope. The measurements can be made by laboratory staff with the minimum of training. The information gained from the measurements has the unique advantage of representing the past as well as the present, so that each hair is its own control and population standards are not an essential requirement. 
I wish to thank Dr T. Gillman of the ARC Experimental Pathology Department, Babraham, for bringing this problem to my attention and for his valuable advice throughout the progress of this work. I am indebted to Professor H. L. Wallace for permission to undertake this work in his Department and to Dr Joan Scragg for allowing me to study patients under her care. The work was performed during the tenure of a Wellcome Trust Research Travel Grant.

\section{REFERENCES}

Garrow, J. S. \& Pike, M. C. (1967). Br. F. Nutr. 21, 155.

Gillman, J. \& Gillman, T. (195I). Perspectives in Human Malnutrition. New York: Grune and Stratton Scragg, J. \& Rubidge, C. (1960). Br. med. $\mathscr{\%}$. ii, 1759.

Sims, R. T. (1967a). Br. F. Derm. 79, 43.

Sims, R. T. (1967b). Archs Dis. Childh. 42, 397.

Smith, R. (1960). Clin. Sci. 19, 275.

Thompson, M. D. (1955). Br. med. F. ii, 1366.

Trowell, H. C., Davies, J. N. P. \& Dean, R. A. (I 954). Kwashiorkor. London: Arnold.

Waterlow, J. (1959). Nature, Lond, 184, 1875.

Waterlow, J. S., Cravioto, J. \& Stephen, J. M. L. (1960). Adv. Protein Chem, 15, I3 I.

Williams, C. D. (1933). Archs Dis. Childh. 8, 423. 